during intercourse. There were no significant differences between patients and nurses with Crohn's disease $\left(\chi^{2}=0 \cdot 1\right)$ : Neither was there a difference between patients and nurses who were menstruating and those who had been amenorrhoeic for six or more months $\left(\chi^{2}=1 \cdot 3\right)$.

We believe that a substantial number of women with Crohn's disease have largely unrecognised sexual difficulties and that these may be partly responsible for the reduced fertility seen among women with Crohn's disease. ${ }^{5}$ Certainly such difficulties might account in part for the high level of interest in fertility and family planning among self help groups for patients with inflammatory bowel disease. ${ }^{6}$ Physicians, surgeons, gynaecologists, and family practitioners need to be sensitive to the needs of women with Crohn's disease.

\section{A M LichTAROWICZ} J F MAYBERRY

University and City Hospitals,

Nottingham NG8 1PB

1 Mayberry JF, Rhodes J, Hughes LE. Incidence of Crohn's disease in Cardiff between 1934 and 1977. Gut 1979;20:602-8

2 Mayberry JF, Dew MJ, Morris JS, Powell DB. An audit of Crohn's disease in a defined population. $\mathcal{F} R$ Coll Physician Lond 1983;17:196-8.

3 Rees JEP, Mayberry JF, Calcraft B. What the patient wants to know about Crohn's disease. f Clin Gastroenterol 1983;5:221-2.

4 Mayberry JF, Newcombe RG. Are nurses at an increased risk of developing inflammatory bowel disease? Digestion 1981;22:150-4.

5 Mayberry JF, Weterman IT. European survey of fertility and pregnancy in women with Crohn's disease: a case control study by European collaborative group. Gut 1986;27:821-5.

6 Mayberry JF. The role of local self-help groups for patients with inflammatory bowel disease. International fournal of Colorectal Disease 1987;2:15-6.

\section{Children born in Seascale}

SIR,-In the week of the 30th anniversary of the Windscale fire it is surely a remarkable coincidence that your pages should carry confirmation. (3 October, $p$ 819, 822) of the findings of Sir Douglas Black $^{1}$ concerning the raised incidence of childhood leukaemia around the Windscale (now Sellafield) plant. The discovery that the excess is confined to children of mothers living in Seascale at the time of birth raises a number of questions in relation to the continuing controversy over the safety of nuclear installations in Britain.

Firstly, as the Lancet observed after the inquiry, of the 14 young people with leukaemia born in Millom rural district, three were born in 1957the year of the fire-and one in 1958. The findings of Professor M J Gardner and colleagues sharpen the doubts that this small temporal focus have raised.

Secondly, in offering his "qualified reassurance" to the people of west Cumbria Sir Douglas relied heavily on the calculations of the National Radiological Protection Board, which claimed to show that reported levels of radioactivity discharged from the plant were far too low to account for the observed incidence of leukaemia. ${ }^{3}$ Profound uncertainties underlie the models used in these calculations, ${ }^{45}$ but the uncertainties are at their most broad and uncharted over risks to the fetus.

The fetal model ${ }^{6}$ relies on a tiny handful of animal experiments and is preoccupied with changes in physiology during gestation rather than with metabolic behaviour. Thus the fractional distribution of plutonium in the organs of the fetus is taken to be the same as that in the mother Transfer of actinides from mother to child is based entirely on experiments in animals; the authors of the model remark that extreme care is needed in extrapolating from animals to humans. They also question whether the conventional concept of dose has any meaning when applied to the fetus. It seems unlikely that committed effective dose equivalent; which is the quantity recommended for adult members of the population, is an appropriate criterion for estimating risks to the fetus. ${ }^{6}$

The model also includes a factor to account for the reciprocal relation between tissue dose and the increasing body mass of the growing child. Thus the dose-and therefore the risk arising - from a long lived $\alpha$ emitter lodged in the skeleton is taken to decrease with the rapid growth in fetal body mass. ${ }^{6}$ Tissue mass is relatively unimportant, and at the cellular level $\alpha$ particle dose averaged throughout the tissue may be biologically almost meaningless. ${ }^{7}$

Thanks to the work of Professor Gardner and his colleagues, those seeking an explanation for the existing excess of leukaemia in Seascale now have a clearer idea of where their efforts might be directed.

Science Policy Research Unit,

David Crouch

University of Sussex,

Bniversity of Sussex

1 Black D. Investigation of the possible increased incidence of cancer in west Cumbria. London: HMSO, 1984

2 Anonymous. The main lesson from Sellafield [Editorial]. Lancet 1984;ii:266-7.

3 National Radiological Protection Board. The risks of leukaemio and other cancers in Seascale from radiation exposure. Didcot: NRPB, 1984.

4 Crouch D. Science and trans-science in radiation risk assessment: child cancer around the nuclear fuel reprocessing plant at Sellafield, UK. Sci Total Environ 1986;53:201-16.

5 Crouch $D$. The role of predictive modelling: social and scientific problems of radiation risk assessment. In: Russell Jones $R$,
, problems of radiation risk assessment. In: Russell Jones R,
Southwood R, eds. Radiation and health. Chichester: Wiley,

6 Adams $\mathrm{N}$, Stather JW. Irradiation of the foetus from maternal intakes of plutonium. Radiol Prot Bull 1984;58:31-6.

7 Mole RH. The biological basis of plutonium safety standards. f Br Nucl Energy Soc 1976;15:203-13.

\section{Keeping up with orthopaedic epidemics}

SIR,-The suggestion by Mr Christopher Bulstrode that the rising incidence of fractured neck of femur is responsible for the present difficulties experienced in running orthopaedic trauma services (29 August, p 514) has been challenged by Dr Fear and colleagues (26 September, p 782). They produce data from Leeds to show that the incidence of fractured neck of femur and the actual number of cases in the over 65 age group have not changed noticeably in the past 12 years.

When figures for the Cardiff Royal Infirmary (table) are considered in two five year periods,

Numbers of operations for fractured neck of femur and trauma cases at the Cardiff Royal Infirmary between 1977 and 1986

\begin{tabular}{ccc}
\hline Year & $\begin{array}{c}\text { Total operated } \\
\text { on for fractured } \\
\text { neck of femur }\end{array}$ & $\begin{array}{c}\text { Total operated } \\
\text { trauma cases }\end{array}$ \\
\hline 1977 & 407 & 1493 \\
1978 & 390 & 1566 \\
1979 & 382 & 1603 \\
1980 & 379 & 1654 \\
1981 & 382 & 2218 \\
1982 & 427 & 1854 \\
1983 & 398 & 2092 \\
1984 & 403 & 1938 \\
1985 & 463 & 2211 \\
1986 & 454 & 2228 \\
\hline
\end{tabular}

1977-81 and 1982-6, operations for fractured neck of femur increased by $10.5 \%$ and all trauma operations by $21 \%$. The incidence of fractured neck of femur is rising gradually as the population ages but is overshadowed by a more rapid rise in general trauma. The motorcycle has taken over from the car as a major cause of trauma since the widespread use of seatbelts; and knee arthroscopy becomes daily more popular, as does the operative fixation of secondary bony deposits of malignant disease.

Many other factors heap pressure on limited resources. To date the "epidemic" has been contained as far as theatre time is concerned and with little expansion in resources by the introduction of better $x$ ray imaging, orthopaedic fixation, and anaesthetic techniques.

Clearly, a time will be reached when the elective case will be squeezed out by the trauma load, especially if the beds happen to be under the same roof.

Cardiff Royal Infirmary,

T R Austin

Cardiff CF2 1SZ

\section{Reference bias in reports of drug trials}

SIR,-I would like to commend Dr Peter Gøtzsche for his study of "reference" bias in reports of drug trials (12 September, $p$ 654). It is dismaying that unbiased information retrieval should be so difficult. The modern meta-analyst or other researcher of is faced with the challenge of collecting an unbiased series of reports for a given subject using the combination of an electronic searching system that $O$ provides incomplete retrieval of reports and a hand $\vec{\circ}$ search method that relies on a biased set of reports.

I would also like to commend $\mathrm{Dr}$ Robert Newcombe for presenting the concept of "registering" protocols for peer review at the planning stage $N$ (p 656). Readers may be interested to know that Jerold Lucey, editor of Pediatrics, has indicated his willingness to adopt a system similar to that proposed by Dr Newcombe.

Dr Newcombe's arguments for a registration system would have been a good deal stronger if he had supported his statements about publication bias with data. Though there are data to support its existence in psychology and education,,$^{12}$ publication bias is far from being a fact supported by data in medicine. As far as I know, a study by Simes provides the only published data documenting the problem, in this case for cancer. ${ }^{3}$ Findings from an additional study ${ }^{4}$ show that a publication bias $\overline{\bar{O}}$ related to study results does exist but there it is the authors who fail to write up null or negative results rather than the editors who fail to accept them for publication.

Dr Newcombe wrote that currently the only prospect of eliminating publication bias is to contact all investigators who may have done rele- $\bar{\sigma}$ vant work; he mentioned the worldwide survey designed to identify all unpublished trials in peri- : natal medicine, undertaken by Iain Chalmers and others in connection with the Oxford database of $\mathrm{O}$ perinatal trials. The survey is now complete, and the results are being written up. Very few responses $N$ were received reporting unpublished results of $D$ perinatal trials, indicating that there are not many unpublished results of trials, that the survey did not reach investigators with unpublished results, or that investigators with unpublished results $\omega$ did not respond to the survey. In any case, we are forced to conclude that retrospective registration 0 of trials is not worth while in view of the enormous effort and expense required. Instead, we must $\stackrel{\mathcal{C}}{\rightarrow}$ devise a system for prospective registration of 0 initiated studies, as Dr Newcombe and others have $\bar{o}$ suggested.

Though the proposal to register studies through journals is a possible solution, the additional 0 burden might prove too great for the already overloaded volunteer peer review system. Perhaps 8 a more practical approach, at least in the United $\frac{0}{0}$ States, would be to set up registration through the institutional review boards, a system already in 